\title{
Implementing a Service of Independent Living Using a Participatory Approach
}

\author{
Ivan Traina \\ Department of Education Studies, University of Bologna, Bologna, Italy \\ Email: ivan.traina@unibo.it
}

Received 6 April 2016; accepted 22 April 2016; published 25 April 2016

Copyright (C) 2016 by author and OALib.

This work is licensed under the Creative Commons Attribution International License (CC BY). http://creativecommons.org/licenses/by/4.0/

(c) (i) Open Access

\section{Abstract}

This paper presents a case study about the implementation of a service of independent living using a participatory approach. The service promoted living experiences in apartments with innovative activities, characterized by means for the development of personal autonomy addressed to persons with disabilities and older persons. The paper shows the methodology applied, the experimentation process and the lessons learnt from the experience. Realized in the framework of the doctoral thesis titled "Social inclusion of vulnerable groups through participatory and emancipatory approaches. Implementing active citizenship and socially innovative actions in the framework of civil \& human rights model of disability". The implementation of the service has allowed demonstrating the initial research hypothesis according to which "an open participation in the cocreation of a service makes life easier for vulnerable groups", gaining more knowledge about how to involve vulnerable groups as co-creators of services. This aspect can support the shift from situations based only on medical approach (passive situation), towards ones based on human rights (active situation). Placing the person with her/his needs, desires, objectives and expectations at the centre of actions and interventions.

\section{Keywords}

Participatory Approach, Independent Living, Autonomy, Living Lab, Vulnerable Groups

Subject Areas: Education, Sociology

\section{Introduction}

In this paper, I will explore an empirical case study implemented using a participatory approach [1]. It was realized in collaboration with AIAS Bologna Onlus ${ }^{1}$ and Emilia-Romagna’s Center for Assistive Technology of Corte Roncati ${ }^{2}$.

${ }^{1}$ Available at: http://www.aiasbo.it/.

${ }^{2}$ Available at: http://www.ausilioteca.org/cra. 
The case study was aimed at implementing a service of independent living ${ }^{3}$ [2].

This experience represents a "delimited phenomena", as discussed by Flyvbierg [3], observed over a precise period of time. The population was heterogeneous rather than homogenous, and involved a small group of participants. This means that the results of the analysis and the insights gained don't allow the presentation of conclusions for understanding a larger number of cases, but permit focus on confirmatory aspects-rather than disconfirmatory [4] [5] —in relation to the initial hypothesis of research.

The participants represented a specific population, and not a sample representative of any conditions—or part—of people with disabilities.

For this reason, the case study analysed considers mainly the processes that people have directly lived and judged. Especially in relation to the questions about "how" and "how much" participatory approaches can make life easier for vulnerable groups [6] [7].

Exploring how persons with disability can face different situations, considering as central their role, needs, desires, objectives and perspectives.

The implementation of the service was developed involving participants, as discussed elsewhere [8]-[13]. Adopting an innovative participatory method, the Living Lab, as example on how to put into practice theoretical concepts referred to the topic of participation, as discussed by Kusiak [14], Ståhlbröst [15] and Pallot [16].

As approach that can help to foster the shift from a situation of passivity, sickness and patient care-often characterizing persons with disability - towards new scenarios of active role in the elaboration of life projects. Demonstrating that facilitating the participation in planning of processes or design of actionscan lead to socially innovative scenarios where an active role becomes possible. Scenarios, in which services become more accessible and easier to use for all, support ultimately a greater inclusion [17]-[19].

\section{Methodology}

\subsection{Participatory Approach}

The participatory approach applied for the development of the service of independent living was focused on two aspects of participants.

The first is inherent to the experience carried out during the weekends and within the Living Lab meetings, through which the participants have contributed to the design and implement the service [20].

The second concerns the active role in using environments, tools and assistive technology to increase the level of autonomy and independence. This kind of contribution is more spontaneous and less dependent by structured methods of participation—such as the Living Lab.

It provides a positive value either for the individual, in terms of self-determination, empowerment and rise of self-confidence [21], and for the service that can benefit from suggestions and ideas resulting from the real needs of participants.

These two aspects of participation were defined in order to avoid the involvement of participants only as simple "testers" or "users", roles that do not allow the co-design or co-creation of a service.

\subsection{Analysis Conducted}

The analysis conducted was based on four assumptions:

1) The first assumption began as I drew upon my developing theoretical understanding of participatory approach.

2) The second focused on the initial research question "can an open participation in the co-creation of the services makes life easier for vulnerable groups?”.

3) The third, formulated within an inclusive approach, according to which it is important to shift from a system based on the medical approach of interventions with vulnerable groups, towards a model based on the Human Rights, in order to enhance person's emancipation [22] [23].

4) The forth based on the attempt to avoid deterministic beliefs about disability and associated ideas that exclude the possibility of achieving goals. Trying to shift from a situation of passivity, sickness and patient care to a new scenario based on the person's commitment and participation in the elaboration of his/her own project of life.

${ }^{3}$ The term used to nominate the service was "Smarthomes for independent living”, and indicates apartments provided with home automations and assistive technologies. 
I used these assumptions to support a deductive approach to the preliminary analysis of the data. Thus, I was engaged in a further iterative process in which I reflected on practice through the lens of my developing theoretical ideas.

I also combined this with a more inductive approach, allowing further ideas and concerns relating to the concepts of participation, as they emerged from interviews, observations and meetings, which in turn helped to shape the themes of my analysis.

Whilst there are, inevitably, connections and overlaps between these assumptions I did not see these as problems in my analysis, but rather as challenges.

\subsection{Instruments of the Analysis}

The analysis method was based on participant observations during:

-Coordination meetings.

-Weekends of autonomy spent in the apartments (Smart Homes).

-Living Lab meetings.

The tools reported below have been used by participants in order to report their experiences, and by the professionals to monitor and assess the activities carried out:

-Questionnaires.

-Interviews.

-Focus groups

- "One diary of the experience" written by the participants.

The observations have covered a period of more than one year (November 2012-December 2013).

\section{Experimentation Process}

The experimentation process was designed in order to analyse the requirements for developing and implementing the service of independent living. Three levels were taken into account:

-Micro level: the focus was on psychological aspects, either for the group of participants and the professional educators involved in the weekends of autonomy.

-Meso level: the analysis considered the perception of the service, by the group of participants, the educators and the other professionals involved in the experimentation.

-Macro level: costs, involvement of network's institutions, roles and responsibilities were investigated.

The preliminary phase of the experimentation was organized through meetings between the different institutions and the participants involved in the weekends of autonomy. In particular:

-Meeting with the network of institutions in order to define the management of logistic aspects and organizational issues.

-Meeting with the group of participants for: functional assessment made by the staff of the assistive technology center; collection of information about objectives and expectations; preparation of the apartments.

-Training course on the use of the apartments, addressed to the professional educators participating in the weekends of autonomy, and aimed at raising awareness, understanding and familiarizing with the equipment, aids, assistive technologies and home automations within the apartments.

During the implementation n. 6 coordination meetings were organized between the institutions responsible for the realization of the experimentation: Emilia-Romagna's Center for Assistive Technology of Corte Roncati, the District of Porretta Terme, the ASC INSIEME, AIAS Bologna Onlus, PassoPasso Association and Cooperative Libertas, with the objective of analysing the strengths and weaknesses arising during this phase.

The experimentation process was structured following the logic of the "Living Lab" method, as discussed by Markopouls [24], Santoro [25] and Schumacher [26]. Logic used also for the involvement of the group of participants. Through this, participants became co-designers and co-creators of the service. Providing ideas, suggesting solutions and giving feedback, testing and setting procedures, equipment, aids and technologies on the base of their real needs.

The monitoring phase was recorded using the following tools:

-Coordination meetings.

-Feedback collected through the Living Lab meetings.

-The disabilities of the arm, shoulder and hand (DASH) questionnaire. 
-The instrument Individual Prioritised Problems Assessment-IPPA [27], for outcome analysis in occupational rehabilitation ${ }^{4}$ (this was used also for the definition of the structure of the interviews for gathering other information, including the level of participation).

-"Diary of the experience", written and used by the group of participants to report problems and needs, suggest possible solutions and ideas, on the basis of what emerged during the weekends of autonomy.

-Interviews and focus groups with all the participants, including two professional educators involved in the weekends of autonomy, the professionals of the assistive technology center, and the responsible of the different institutions.

\subsection{Participants}

The group of participants was composed of $n .4$ young persons with disabilities and two professional educators. The group was already involved in means of autonomy promoted by a three years project called "Pathways to independence".

The participation in this experience had provided them with the opportunity to be involved as active co-creators of the service of independent living.

In particular through the provision of suggestions and advice to find solutions for adapting the apartments for everyday living experiences.

This experience allowed them to enrich their lives including the possibility of living in a barrier-free environment with special equipment, such as home automation applications and technological aids.

The group of participants included: two males and two females with different disabilities, aged between 19 and 20 years, and with the following diseases:

a) E.: mild-delay at the cognitive level.

b) A.: hemiparesis and mid-delay at the cognitive level.

c) M.: slight-delay at cognitive level.

d) F.: spasticity.

The group of participants in the weekends included also two educators and one coordinator of the logistic and organizational issues.

Concerning the development of the service, other participants were involved, such as the technical staff of the assistive technology center, one physical therapist, one professional educator and one engineer.

\subsection{Setting}

The apartments used for the development and implementation of the service are located within Emilia-Romagna's Center for Assistive Technology of Corte Roncati.

The apartments have been designed as barrier-free environments for experimenting and evaluating: accessibility solutions, accessories, aids, assistive technologies and home automations. Especially addressed to persons with disability, elderly people and their operators.

These apartments are used also for training courses addressed to rehabilitation professionals, social caregivers, engineers, designers and educators.

The disability of reference influencing the characteristics of the apartments and equipment are: physical, motor, multiple disabilities, cognitive and sensory impairments. Figure 1 and Figure 2 show the house-plants and some imagines of the apartment.

The main features of the apartments are as follows:

a) Apartment at ground floor (80 s.q.m.), for two young persons and one educator, high-technological flat characterized by:

-Orientation of a user with severe motor disability, serious and limited autonomy in daily life.

-Assistive technologies and home automations.

-Attention to the functions of care for the caregivers.

b) Apartment on the first floor (50 s.q.m.), for two young persons and one educator, medium technological flat characterized by:

-Orientation for users with moderate physical disabilities, with partial autonomy in daily life.

${ }^{4}$ These tools were used by the physical therapist and the professional educator of the Emilia-Romagna's Center for Assistive Technology of Corte Roncati to assess functional requirements, accessibility and evaluation of the ability to perform certain activities in the apartments. 

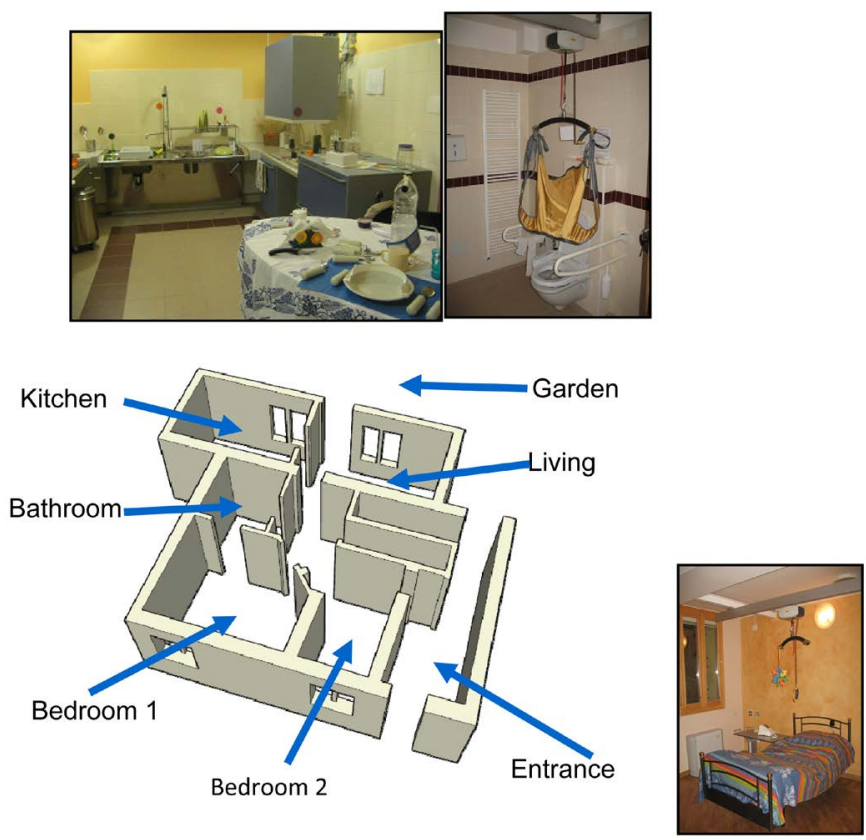

Figure 1. Imagines of the Smart Home at ground floor.

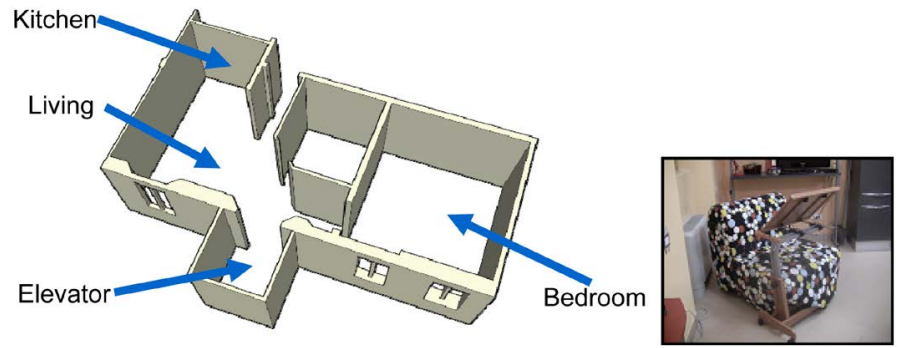

Figure 2. Images of the Smart Home on the first floor.

-Assistive technologies focused on solutions for facilitating daily life and ergonomics.

The apartments are among the most innovative in Italy for the provision of aids, equipment and assistive technologies aimed at improving means of autonomy.

The purpose of developing a service of independent living was aimed at increasing the range of activities by persons with disabilities, whether congenital or acquired.

The apartments were made more suitable for daily life, through the involvement and feedback of the group of participants, collected during the weekends of autonomy, the Living Lab meetings and the adaptations made by the technicians and engineers of the assistive technology center. This shifted the apartments from a use of "showroom", to one of barrier-free and accessible apartments "to be lived in".

\subsection{Institutions Involved}

The institutions involved in the experimentation were:

- USL Bologna and Emilia-Romagna's Center for Assistive Technology of Corte Roncati, in charge of:

-Definition of the procedures for the use of the apartments.

-Development of tools for: scheduling, documenting the experience and evaluating the level of satisfaction of the participants.

-Providing technical support and monitoring the experiences during the weekends.

-Training of staff involved.

-Customization, management and maintenance of equipment, aids and technology used in the apartments during the weekends of autonomy. 
- District of Porretta Terme, Socio-Health Unit “Adult with disability” and District of Casalecchio di RenoASC INSIEME Consortium for Social Interventions, in charge of:

-Elaboration of the annual planning of the project "Pathways of independence" addressed to persons with disabilities.

-Monitoring and assessment of technical interventions required for the customization and adaptation of the apartments, on the base of the documentation produced and the feedback provided by the group of participants.

-Participation in the training activities and coordination meetings.

- AIAS Bologna Onlus, in charge of the management of logistical and organizational issues, including:

-Management of the network of institutions involved.

-Customization of apartments.

-Provision of training and information for use of environmental resources (aids, technologies, etc.).

-Cleaning the apartments.

-Contribution to the documentation of the experience.

- PassoPasso Association, in charge of:

-Promotion of the experimentation.

-Participation in the monitoring and assessment of the activities carried out.

-Management of the relations with the families involved.

- Cooperative Libertas, in charge of providing two professional educators to support the group of participants during the weekends of autonomy.

- Department of Educational Studies-University of Bologna, in charge of observing and analysing the experience as a case study, through participation in the Living Lab meetings and the realization of interviews and focus groups with the participants involved.

\section{Lessons Learned}

The lessons learned from this case study focuses on the results of the experimentation analysed through the lens of the participatory approach.

In fact, this approach has influenced the outcomes of the experimentation in a positive way (as reported below in the interviews and focus groups realized).

Strengths and weaknesses of the experimentation have indeed influenced and have been influenced by the features of participants' involvement.

Concerning the strengths: the experimentation carried out differs from others experiences realized within types of occupational therapy or physiotherapy. While these only have purpose related to functional assessment and rehabilitation, the experimentation observed has an "inclusive educational aim" (without excluding other aims to the rehabilitation).

The social-health care context in general-if not always-lacks this aim. In the case, the professionals involved assumed a maieutic role in supporting and encouraging the independence of the group of participants. In addition, the participants contributed not as "testers or users", but rather as co-creators of a service.

This aspect allowed a rise in awareness and better understanding of what can be achieved with aid, supports and greater autonomy. That ultimately increased self-determination and self-esteem. The inclusive educational aim has influenced and benefitted all persons involved, through the realization of an environment characterized by mutual collaboration, sharing and participation. Creating a sort of virtuous spiral cycle.

Weaknesses were related to organizational bonds that often didn't allow for practicing innovative methods of participation. In this case, it has provided the possibility of a new window of cultural horizons, characterized by greater participation and involvement in the definition of services, shifting from a situation of "customer satisfaction" to new one of "customer participation".

The high number of institutions involved in the implementation of the service of independent living caused a certain level of complexity in the coordination and management of resources, spaces and communications.

The lesson learned is that in order to encourage other similar experiences of participation in developing services, cultural changes are necessary in organizations, including the processes and practices of the institutions involved.

Returning to the initial research hypothesis "can an open participation in the co-creation of the services makes life easier for vulnerable groups", this case study has demonstrated that the institutional culture must become more "open to participation", in order to make services provided and life easier for all. 


\subsection{Participants' Point of View}

The participants' point of views was investigated through different instruments, such as questionnaires (DASH and IPPA), Living Lab meetings, interviews and the collection of information reported in the diary of the experience written by the group of participants.

This tool was used to provide suggestions and ideas about support, adaptations or customizations of aids. It was also useful to understand better the level of autonomy when using aids and technologies aimed at improving independence at home.

The following words were declared by one participant in an interview realized for a television channel ${ }^{5}$ to disseminate the experimentation' results:

“...referring to our experience in the apartments, talking about the great importance of aids that have allowed us to discover new ways to perform everyday activities are possible... Some of these aids were then adopted and used in our homes too, with an evident improvement in the quality of life. An important part of our experience was the collaboration with engineers and designers to improve the functioning of aids and supports with practical solutions, on the basis of our needs".

Another important aspect highlighted by participants during the experience is that it was an opportunity to acquire more knowledge and information about the variety of aids, assistive technologies and home automations available. As stated by a participant during a focus group:

"...the use of these apartments improves our quality of life because we get to know and become more aware of the aids that are available on the market".

The participation in the development of the service provided not only the opportunity to know and become more aware about the supports available on the market, but also to find personal solutions in their use, testing their functionality and possibility of adaptation before purchasing. The participation also allowed the group of participants to feel listened to and taken seriously as adults, with their own challenges, needs, desires, ideas and solutions.

This aspect promoted the achievement of new capabilities, encouraging accountability, self-confidence, self-determination and the use of creativity for the solution of everyday problems. As for instance in one case when preparing a dish of pasta, or in another being able to access and use the bathroom in autonomy.

It is also interesting to report some feedback from the families to show and support the initial hypothesis of research on how an open participation in the co-creation of services-in this case of independent living in apartments provided with home automation — has made life easier, especially for two of them. As stated by the mother of F.:

“...F. at home shows a greater autonomy, now he prepares breakfast, lays dishes on the table and manages everything alone, such as the microwave, and takes more decisions by himself”'

Another interesting feedback was provided by the mother of M., according to which:

"...M. is very happy and enthusiastic about this experience which makes him more independent from authorities and even his family. Now he goes to the supermarket alone and cooks for his brother too. He has also improved in terms of awareness about his personal skills".

From this feedback it's possible to recognize that participation can contribute to the rejection of deterministic beliefs and create new scenarios where vulnerable groups can be the leading participants of a shift from a situation of passivity to one based on the person's commitment and active role in the elaboration of his/her own project of life.

\subsection{Professionals' Feedback}

The professionals' feedback was gathered through interviews and focus groups. The feedback of the two professional educators involved in the weekends of autonomy were very positive. Especially about the level of participation and emancipation achieved by the group of participants. Among the positive aspects described by educators, there is the fact that the group of participants was:

${ }^{5}$ Available at: http://www.youtube.com/watch?v=5-_glaCgQHI\&feature=player_embedded\#at=17. 


\section{“...the first agent in producing change".}

As stated, the possibility of sharing the experiences of autonomy in the apartments has given the opportunity to:

“...increase synergies and skills that an individual alone would not”.

Highlighting the importance of the group dimension for the achievement of new skills and competencies.

In addition, the educators affirmed that the possibility to use supports, provide feedback for a better adaptation to participants' needs, and consequently for finding the best solutions to carry out everyday activities:

“...the experience has helped the participants to increase awareness about their possibilities. And I think this was the biggest goal achieved".

The participatory approach, according to educators, has also allowed the strengthening of the group's relationships and dynamics, both in a positive way, with regard to the sharing of experiences aimed at achieving a greater autonomy. And in a negative way, due to a sort of over-focus on their own individual needs (therefore not always attentive to those of others).

The educators claimed that the emancipation of the group of participants also increased.

This was demonstrated by the increased capability of preparing food, washing the dishes and using the bathroom in autonomy, for instance, contributing to:

“...believing more in their own potential and possibility of independence”.

This allowed the achievement of many of the objectives already foreseen in the three years project called "Pathways to Independence".

The support they have received has also been a very positive aspect, attentive and respondent to their needs. A key element to avoid is that the participants are seen as only testers of a service, when indeed they should be involved as co-creators of service.

The support provided by staff members of the assistive technological center played a fundamental role, the availability of welcoming any requests of customization or adaptation, and their useful reflections.

For aspects related to the usability of tools and accessibility of the environments - to enable the realization of the experiences of independent living — and in terms of participation. It is precisely on this point an interesting recognition was:

“... in situations like those faced during the experimentation, if it is important to ask for a change of perspective to persons with disability when they act for a greater involvement-and thus participation-it is equally important to ask for a change also to the operators and professionals. They too often still think in terms of "I know what you need".

\subsection{Institutions' Evaluation}

The evaluation provided by the different institutions involved was positive. An example is as follows:

“...autonomy is an important sphere of people's lives, it is a basic element to be searched for in order to gradually improve the quality of life of each person. This is what has been put into practice during the weekends of autonomy".

In accordance with this affirmation, it is useful to consider a possible limit highlighted during an interview with a representative of one of the institutions involved. This limit concerns the fact that it may not be possible for the participants to continue the experience of new or greater autonomy at their own home.

Therefore, any achievements gained could remain confined only to a specific time and dedicated environment. In order to avoid this limit, the role and contribution that could be provided by families is very important, so as to exploit the potential improvement of aspects such as independence, autonomy, self-determination, empowerment and emancipation, outside the boundaries of "safe situations".

\section{Final Remarks}

The implementation of the service of independent living using a participatory approach has allowed demon- 
strating the initial research hypothesis according to which "an open participation in the co-creation of a service, makes life easier for vulnerable groups". Gaining more knowledge about how the involvement of vulnerable groups such as becoming co-creators of services, research, products or environment can facilitate their lives.

My contribution to the body of knowledge of participatory approach has been outlined with the aim to investigate the theoretical background and to analyzing a case study focused on how to apply this approach in the intervention with vulnerable groups, in particular persons with disabilities.

The general objective of the study was to further advance the understanding of the potential of participatory approach in terms of inclusion, with a special emphasis on the involvement, empowerment and self-determination of persons, as advocated from the perspective of the Human Rights.

The specific objective consists in to assessing if this approach-once applied-is able to effectively support the shift from situations based on a medical approach (passive situation), towards ones based on human rights (active situation). Placing the person with her/his needs, desires, objectives and expectations at the centre of actions and interventions. Introducing an "inclusive educational aim" in a context usually characterized mainly by rehabilitation and functional assessments.

Moreover, since participation has the explicit intention "to do real things" with "real people", it needs to become more pervasive in many different contexts in order to construct the reality we wish to achieve.

Since the 2015, the service implemented and analyzed as case study has become a "real service". Provided to different associations by Emilia-Romagna's Center for Assistive Technology of Corte Roncati. The apartments during the week have maintained their role as "showroom" apartments. It means that persons can access and visit the home automation solutions and technological aids.

During the weekend, they are used to host small groups of disabled people (accompanied by caregivers, educators, families or friends) to allow to live real experiences of autonomy and independent living.

\section{Future Trajectory of Research}

During my study, I have identified some aspects that I believe are important to do more research about. These aspects are related to the need of more understanding and realization of experiences of inclusive practices.

Not only with educational purposes, but also with the wider aim to shift from a situation of passivity to a new scenario based on the person's commitment in the elaboration of his/her own project of life.

I have also identified the need to further explore tools that can contribute to create scenarios in which services become more accessible and easier to use, favoring ultimately a greater inclusion.

When it comes to understanding the participation as an innovative approach, I have acknowledged that there is a need of more research about practices in order to have more insight into how this approach can support changes in society at large.

Furthermore, I have recognized that in the future we need to develop more experiments, research and practices with the involvement of vulnerable groups.

There are several aspects that need to be understood, if participatory approach should have a sound scientific foundation and be able to grow. Because the involvement of vulnerable groups as co-creators of knowledge or service is the key principle to moving toward future trajectory of research.

\section{References}

[1] Björgvinsson, E., Ehn, P. and Hillgren, P. (2010) Participatory Design and “Democratizing Innovation”. Proceedings of the 11th Biennial Participatory Design Conference, ACM, New York, 41-50. http://dx.doi.org/10.1145/1900441.1900448

[2] Yin, R.K. (2003) Case Study Research: Design and Methods. 3rd Edition, Sage, Thousand Oaks, 109-140.

[3] Flyvbierg, B. (2006) Five Misunderstandings About Case Study Research. Qualitative Inquiry, 12, 219-245. http://dx.doi.org/10.1177/1077800405284363

[4] George, A.L. and Bennett, A. (2004) Case Studies and Theory Development in the Social Sciences (BCSIA Studies in International Security). The MIT Press.

[5] Gerrin, J. (2006) Case Study Research: Principles and Practices. Cambridge University Press, New York. http://dx.doi.org/10.1017/CBO9780511803123

[6] Aragall, F., et al. (2003) European Concept for Accessibility. Editor: Info Handicap. Luxembourg. www.eca.lu

[7] Aragall, F. and Montana, J. (2011) The H.U.M.B.L.E.S. Method for User-Centred Business. Gower Publishing Com- 
pany, USA.

[8] Forester, J., Pitt, J. and Welsh, J., Eds. (1993) Profiles of Participatory Action Researchers. Department of Urban and Regional Planning, Cornell University, Ithaca.

[9] Kemmis, S. and McTaggart, R. (2001) Participatory Action Research. In: Denzin, N. and Lincoln, Y., Eds., The Handbook of Qualitative Research, 2nd Edition, Sage, Thousand Oaks, 567-605.

[10] Kemmis, S. and McTaggart, R. (2005) Participatory Action Research: Communicative Action and the Public Sphere. In: Denzin, N. and Lincoln, Y., Eds., The Sage Handbook of Qualitative Research, 3rd Edition, Sage, Thousand Oaks, 559-603.

[11] Kemmis, S. (2006) Participatory Action Research and Public Sphere. Educational Action Research Journal, 14, 459-476. http://dx.doi.org/10.1080/09650790600975593

[12] Kemmis, S. and McTaggart, R. (2007) Participatory Action Research: Communicative Action and the Public Sphere. In: Denzin, N. and Lincoln, Y., Eds., Strategies of Qualitative Inquiry, Sage, Thousand Oaks, 271-330.

[13] Krishnaswamy, A. (2004) Participatory Research: Strategies and Tools. Practitioner: Newsletter of the National Network of Forest Practitioners, 22, 17-22.

[14] Kusiak, A. (2007) Innovation: The Living Laboratory Perspective. Computer-Aided Design \& Applications, 4, 863-876. http://dx.doi.org/10.1080/16864360.2007.10738518

[15] Ståhlbröst, A. (2008) Forming Future IT—The Living Lab Way of User Involvement. Luleå University of Technology, Department of Business Administration and Social Sciences, Division of Informatics, 2008:62.

[16] Pallot, M. (2009) Engaging Users into Research and Innovation: The Living Lab Approach as a User Centred Open Innovation Ecosystem. http://www.cwe-projects.eu/pub/bscw.cgi/1760838?id=715404_1760838

[17] Mace, R.L., Hardie, G.J. and Place, J.P. (1996) Accessible Environments: Toward Universal Design. North Carolina State University, Raleigh.

[18] McIntyre-Mills, J. (2010) Participatory Design for Democracy and Wellbeing: Narrowing the Gap between Service Outcomes and Perceived Needs. Systemic Practice and Action Research, 23, 21-45. http://dx.doi.org/10.1007/s11213-009-9145-9

[19] Priestley, M., Waddington, L and Bessozi, C. (2010) New Priorities for Disability Research in Europe: Towards a User-Led Agenda. Disability \& Society, 25, 731-746.

[20] Tandon, R. (2005) Participatory Research. Revisiting the Roots. Mosaic Publications, New Delhi.

[21] Wehmeyer, M.L. and Abery, B. (2013) Self-Determination and Choice. Intellectual and Developmental Disabilities, 51, 399-411. http://dx.doi.org/10.1352/1934-9556-51.5.399

[22] Quinn, G., Degener, T., Bruce, A., Burke, C., Castellino, J., Kenna, P., Kilkelly, U. and Quinlivan, S. (2002) Human Rights and Disability. The Current Use and Future Potential of United Nations Human Rights Instruments in the Context of Disability. United Nations, New York and Geneva.

[23] Stein, M. (2007) Disability Human Rights. Faculty Publications. Paper 264. http://scholarship.law.wm.edu/facpubs/264

[24] Markopoulos, P. and Rauterberg, G.W.M. (2000) Living Lab: A White Paper, 35, I. A. P. R.

[25] Santoro, R. and Conte, R. (2009) Living Labs in Open Innovation Functional Regions. 15th International Conference on Concurrent Engineering (ICE 2009), Leiden, 22-24 June 2009.

[26] Schumacher, J. and Feurstein, K. (2007) Living Labs-A New Multi-Stakeholder Approach to User Integration. 3rd International Conference on Interoperability of Enterprise Systems and Applications (I-ESA'07), Funchal, 26-30 March 2007.

[27] Wessels, R., Persson, J., Lorensen, Ø., Andrich, R., Ferrario, M., Oortwijn, W., Van Beekum, T., Brodin, H. and de Witte, L. (2002) IPPA: Individually Prioritised Problem Assessment. Technology and Disability, 14, 141-145. 